\title{
The Ethics of Neuroeducation: Research, Practice and Policy
}

\author{
Bruce Maxwell • Eric Racine
}

Received: 29 February 2012 /Accepted: 12 March 2012 /Published online: 5 April 2012

(C) Springer Science+Business Media B.V. 2012

\section{Introduction}

The recent publication of a report of the Royal Society [1] titled "Neuroscience: Implications for education and lifelong learning" in early 2011 captures the current excitement and promises surrounding the prospect of informing educational practices with the results of contemporary neuroscience. This report reviews for a general audience the basic principles of brain plasticity, reward systems, and self-regulation. Illustrative of a strong emerging trend, it highlights the need to "bridge the gulf between educators, psychologists and neuroscientists" and to provide "high quality information" in the "rush to apply so-called brain-based methods". Indeed, the application of neuroscience to educational problems, referred to as "neuroeducation" or "educational neuroscience," has been a mixed success. On the positive side, neuroimaging data have helped move forward the debate over whether dyslexia is a visual

\section{B. Maxwell}

Department of Education, University of Québec, Trois-Rivières, Ringuet building, room 2061, 3351 boul. des Forges, Trois-Rivières, QC, Canada G9A 5H7

e-mail: bruce.maxwell@uqtr.ca

\section{E. Racine $(\bowtie)$}

Neuroethics Research Unit, Institut de recherches cliniques de Montréal (IRCM), 110 avenue des Pins Ouest, Montréal, QC, Canada H2W 1R7

e-mail: eric.racine@ircm.qc.ca perceptual or phonological disorder. Educators are also turning increasingly to neuroscience as an exciting new resource in their work helping children develop and learn. On the other perhaps more negative side, misconceptions about learning and the brain have proliferated. Influenced in part by popular but scientifically dubious "brain-based" educational programmes, neuromyths can inform teachers' instructional choices but promise no benefit for the children they teach. How dangerous are neuromyths and how can educators and policy planners get access to accurate and relevant information about the brain? What are the ethical responsibilities of businesses that create and market neuroeducational products? Does the experience of attempts to marry education with the mind sciences in the twentieth century contain important lessons about pitfalls to avoid in the emerging field of neuroeducation? Can the goals of improving teaching, learning and children's health be better served

\footnotetext{
E. Racine

Department of Medicine and Department of Social and Preventive Medicine, Université de Montréal,

Montréal, QC, Canada

E. Racine

Department of Neurology and Neurosurgery,

McGill University,

Montréal, QC, Canada

E. Racine

Department of Medicine \& Biomedical Ethics Unit, McGill University, Montréal, QC, Canada
} 
through collaborative relationships between neuroscience researchers and educators and policy makers? Is there a professional responsibility among teachers to be informed and critical consumers of science? These largely uncharted questions underscore the importance of examining closely the evolving field of neuroeducation from the standpoint of values and ethical principles. In spite of the important role education plays in our daily lives, neuroethics has centered on other areas like the clinical application of neuroscience, with much less attention dedicated to identifying and addressing the rapid evolution of neuroeducation. This special issue of Neuroethics is dedicated to bringing together contributors to this new literature to make needed headway in this direction.

In their paper "Neuroeducation-a critical overview of an emerging field" Daniel Ansari, Bert De Smedt, and Roland Hugo Grabner, from the University of Western Ontario, (Canada), the Katholike Universiteit (Belgium), and the Swiss Federal Institute of Technology propose an informative, concise and well organized survey of, as the title promises, the new field of neuroeducation. Ansari and colleagues recognized previous mishaps in the development of neuroeducation and consequently take great care in reviewing recent developments in neuroscience that call for and justify greater attention and integration of neuroscience in education. Their essay also supports the concept of neuroeducation as a legitimate scholarly and practical enterprise. To illustrate the translation of neuroscience to education, they present and summarize results in areas crucial to education such as learning (including developmental dyslexia), numeracy and arithmetic, and brain training. Next, the authors then present some of the challenges of neuroeducation. These challenges include that of communication, given neuroscientists' misunderstanding of educationalists and educationalists' misunderstanding of neuroscientists. Training is also an area in need of development to tool educationalists with basic neuroscience knowledge, including dispelling misinterpretations of biological explanations of behaviour. Another area to address explicitly is the management of expectations. Finally, acknowledging methodological limitations of current neuroscience is inescapable. Many of these challenges have been at the core of development of neuroethics [2] and Ansari and colleagues open a unique door for exploring existing literature on the ethical aspects of the public understanding of neuroscience and neuroimaging and its use in education.

In their paper, "The need for interdisciplinary dialogue in developing ethical approaches to neuroeducation research", Paul Howard-Jones from the University of Bristol and Kate Fenton from the University of West of England stress the need to integrate scholarship in ethics and neuroeducation research. They argue that, "many ethical issues in neuroeducational research cannot be appropriately addressed using the principles and guidance available in one of these areas alone, or by applying these in simple combination. Instead, interdisciplinary and public dialogue will be required to develop appropriate normative principles". Informed by results of a survey on 100 educationalists at different stages of their careers, they identify three areas of importance to ethics and educational policy. First, conducting research at the interface of cognitive neuroscience and education raises several ethical issues such as the physical, psychological, social, and educational risks of Magnetic Resonance Imaging (MRI). They also raise and discuss questions about pediatric research ethics and animal research ethics. Second, scrutining and communicating findings and messages constitutes an important task since fMRI research data in particular can be overinterpreted and generate unrealistic expectations. These issues are exemplified by UK discussions surrounding the "dyslexia myth" which Howard-Jones and Fenton examine in detail. They show that, neuroessentialist interpretations of neuroscience data can jeopardize beliefs in agency and consequently bring teachers to adopt or discredit beliefs and interventions hastily. They advance the model of professional "neudoeducators" as a solution to some of these issues. Third, issues of policy involving novel ethical considerations likely to arise in the future include the phenomenon of cognitive enhancers, infant screening with neural markers, and genetic profiling for leaning difficulties. Since many teachers express concerns about the latter innovations in the survey data reported by HowardJones and Fenton, a better understanding of these issues seems key to the development of neuroeducation as part of a broader dialogue between disciplines involved in neuroeducation.

In the paper "Neuroethics, neuroeducation, and classroom teaching: Where the brain sciences meet pedagogy", Mariale Hardiman, Luke Rinne, Emma Gregory, and Julia Yarmolinskaya from the School of Education 
of Johns Hopkins University tackle the classroom teacher's challenge of sorting through the legitimate and sometimes commercially spun promises of neuroscience. Considerable momentum may be lost and energy wasted if teachers lack the advice, training and guidance they need to negotiate so-called "brain-based educational programs". Based on a unique neuroeducation experience at their university, the authors discuss a set of ethical challenges faced by different stakeholders, including practicing teachers, neuroscience researchers, publishers, and the popular media, educational policymakers, and universities. They suggest unique and concrete ways in which these challenges might be surmounted through teacher preparation that would allow teachers themselves to translate findings from neuroscience to design and deliver effective instruction.

In her paper "Moral neuroeducation from early life through the lifespan", Darcia Narvaez from the University of Notre Dame puts forth a bold vision on how neuroscience informs moral development and how neuroscience should inform moral education and early childcare. First, Narvaez stresses the importance of character, experience, and emotion. She then reviews work in epigenetics and discusses how experience influences gene expression. Narvaez concludes that epigenetics plays an active role in shaping individuals and that caregivers can influence significantly the moral development of children. She also introduces the Triune ethics theory she has developed [3], which describes "the mechanisms for neurobiological and relational influences on moral dispositions". This theory incorporates a security ethics, an ethics of engagement, and an ethics of imagination and relies on emotional circuitry developed early in life, which "relates to the brain's architecture for morality and later ethical expression". The development of these different ethical orientations can be compromised in children facing social and emotional deprivation. Second, Narvaez argues for the existence of an Environment of Evolutionary Adaptedness (EEA), a social environment of early development characterized by breastfeeding, touch, responsivity, multiple adult caregivers, play, and social support. She proposes that the approach of Integrative Ethical Education provides a model for the development of virtue in children based on the insights of EEA and contemporary biology. Narvaez' paper relies on a broad range of scholarship and is likely to stir needed debate, especially given the recommendations put forward for research, for policy positions of professional organizations, and for ethical responsibilities of practitioners. These recommendations are particularly suited for further discussion and concrete action and policy in the early days of neuroeducation.

Finally, in a collaborative paper entitled "Does the neuroscience research on early stress justify childcare? Examining interwoven epistemological and ethical challenges", we (Maxwell and Racine) first describe how research on early stress has been depicted both in academic and popular literature. We describe that a "neuroscience argument for early childcare" has emerged of late based on both animal research and a wide range of human studies. This argument advances that the neuroscience of early stress exposures supports for "responsive parenting" as defined in the specialized literature. Such responsive parenting calls for very specific practices (e.g., frequent child-caregiver physical contact, nursing on demand, late weaning and co-sleeping). However, currently, several epistemological limitations mitigate the strength of the neuroscience argument for responsive parenting. Consequently, this attractive argument could fuel unwarranted anxiety in well intentioned parents and, given current limitations that are often overstepped, threaten public confidence in the burgeoning field of neuroeducation.

We hope readers of Neuroethics will discover new questions in this special issue and be stimulated by papers we have collected based on a wide range of perspectives and scholarship. We acknowledge support from the Social Science and Humanities Research Council of Canada and NeuroDevNet, funded by the Networks of Centres of Excellence, a program of the federal government to advance science and technology.

\section{References}

1. Royal Society. 2011. Neuroscience: Implications for educaiton and lifelong learning, 22. London: Royal Society.

2. Illes, J., and E. Racine. 2005. Imaging or imagining? A neuroethics challenge informed by genetics. American Journal of Bioethics 5(2): 5-18.

3. Narvaez, D. 2008. Triune ethics: The neurobiological roots of our multiple moralities. New Ideas in Psychology 26: 95119. 